\title{
Effect of root exudates and rhizobacteria on colonization of barley roots by phytopathogenic fungi Fusarium culmorum
}

\author{
Shaposhnikov A.I. ${ }^{1 *}$, Vishnevskaya N.A. ${ }^{1}$, Shakhnazarova V.Yu. ${ }^{1,2}$, Borodina E.V. ${ }^{1}$, \\ Strunnikova O.K. ${ }^{1}$ \\ ${ }^{1}$ All-Russian Research Institute for Agricultural Microbiology, St. Petersburg, Russia \\ ${ }^{2}$ St. Petersburg State University, Department of Agrochemistry, St. Petersburg, Russia \\ *e-mail:ai-shaposhnikov@mail.ru
}

The studies were aimed at clarifying the question: why Fusarium culmorum in 1-4 days from seeds germination more actively colonized roots that were colonized by Pseudomonas fluorescens, but not sterile roots. Daily and four-day exudates of sterile barley and colonized, separately and jointly, by fungi and bacteria were obtained. The quantitative composition of root exudates and nutrition requirements of the fungi and bacteria was established using an ultra-efficient liquid chromatography. The effect of barley root exudates on the ability of the fungi to colonize barley roots and the nature of the interaction between the facultative phytopathogenic fungi F. culmorum and the antagonistic bacteria $P$. fluorescens has been evaluated. It was established that glucose is the main component of the root exudates used both by the fungi and bacteria. The bacterial strain, more active than the fungi, utilized of organic acids and amino acids. Similar nutritional needs of the fungi and bacteria can lead to competitive relationships between these microorganisms. It has been established that root exudates of barley that were colonized by $P$. fluorescens stimulate the growth of the macroconidium growth tubes of F. culmorum. A comparative analysis of low molecular weight components of root exudates showed that exudates of barley roots that were colonized by bacteria contain a significantly higher amount of glucose and lower amounts of aromatic acids (plant defense compounds having antimicrobial activity) than root exudates of sterile barley. Stimulating the growth of the fungi could be the reason for more active colonization by the fungi of the roots colonized by bacteria. It has been established that both fungi and bacteria that colonizing the roots of barley mainly influenced on the amount of low molecular weight exometabolites, and not the qualitative composition of root exudates. Acknowledgements: These studies were funded by RFBR (project 18-016-00111). 